\title{
Removal of Trihalo Methanes Using Activated Carbon Prepared from Agricultural Solid Wastes
}

\author{
El-Demerdash FM ${ }^{1 *}$, Abdullah $\mathrm{AM}^{2}$ and Ibrahim DA $^{3}$ \\ ${ }^{1}$ University of Alexandria, Institute of Graduate Studies and Research, Department of Environmental Studies, Alexandria, Egypt \\ ${ }^{2}$ Holding Company for water and wastewater, Alexandria, Egypt
}

${ }^{3}$ Alexandria Water Company, Alexandria, Egypt

\begin{abstract}
High chlorine dosages are used in some drinking water plants to overcome the deficiencies in the treatment to at least ensure a supply of microbiologically safe water to the population. This fact and the increment of natural organic matter (NOM) in the aquatic resources due to rainfall increases and anthropogenic activities are becoming a critical concern, due to the formation of chlorination by-products such as trihalomethanes (THM), which are carcinogenic substances. Egypt drinking water system using new treatments is essential to meet the quality guidelines. Trihalomethanes are carcinogenic by-products of disinfection that are present in drinking water. In the present research, adsorption was employed for the removal of THMs found in water supply systems. The effects of $\mathrm{pH}$, contact time, adsorbents and adsorbate concentration on the adsorption system were investigated. The Langmuir and Freundlich adsorption isotherm models were used to analyse the resulting adsorption data. The kinetics of THM removal was found to follow the pseudo-second-order model rather than the Langmuir-Hinshelwood pseudo-first-order model.
\end{abstract}

Keywords: Trihalomethanes; Activated carbon; Agricultural solid wastes

\section{Introduction}

Adsorption is a mass transfer operation in which substances present in a liquid phase are adsorbed or accumulated on a solid phase and thus removed from the liquid. Adsorption processes are used in drinking water treatment for the removal of taste and odour causing compounds, synthetic organic chemicals (SOCs), colour forming organics, and disinfection by-product (DBP) precursors. Inorganic constituents, including some that represent a health hazard, such as perchlorate, arsenic, and some heavy metals, are also removed by adsorption [1,2]. Granular activated carbon (GAC) is used in columns or beds for gas and vapour systems, and also for processing a number of liquids. The carbon must possess sufficient mechanical strength to withstand the abrasion incident to continued use. The development of high adsorptive power is accompanied by loss of mechanical strength and density $[1,3]$. Therefore the activation stage cannot be too short because the carbon would lack needed adsorptive power; conversely, it cannot be too long for then the carbon would be too soft and bulky. Few materials, in their natural state, can be converted into activated carbon with high density and low attrition. Less dense material, however, can be made dense and yield a hard carbon when mixed with a binder. The binder should be a substance which when carbonized does not liquefy or expand. However, some shrinkage is desirable. The tarry byproducts from woods and certain grades of anthracite and bituminous coal have been found to be good binders. To be suitable as a binder, a substance should liquefy or soften during carbonization and swell sufficiently to give a porous structure. Suitable binders include sugars, tar, pitch, and lignin [4].

Powered activated carbon (PAC) used in membrane bioreactor (MBR) employed in the treatment of bleach pulp mill effluents was evaluated. The MBR was operated with hydraulic residence time of $9.5 \mathrm{~h}$ and PAC concentration of $10 \mathrm{~g} / \mathrm{L}$. The addition of PAC to the MBR reduced the average concentration of chemical oxygen demand (COD) the permeate from $215 \mathrm{mg} / \mathrm{L}$ ( $82 \%$ removal efficiency) to 135 $\mathrm{mg} / \mathrm{L}$ ( $88 \%$ removal efficiency), producing an effluent that can be reused on bleaching stage. Moreover, the addition of PAC to the MBR resulted in the reduction in applied pressure and provided a more stable operation during the monitoring period. This occurrence was probably due to the increase of critical flux after the addition of PAC. The fouling mechanism was investigated and the results showed that controlling the concentration of soluble microbial products (SMP) and extracellular polymeric substance (EPS) by using PAC and keeping the operational flux below critical flux is of major importance for MBR operational sustainability [5].

Low cost adsorbents from agricultural waste like rice husk was developed with various activation methods and tested for the removal of aqueous contaminants. Adsorption of a basic dye, malachite green (MG), from aqueous solution onto nitric acid treated (NRH), and peroxide treated rice husk (PRH) have been investigated. Various experiments were studied using batch adsorption technique under different conditions of $\mathrm{pH}$, adsorbent dosage, initial dye concentration, and temperature. The adsorption capacities of MG by the NRH and PRH were essentially due to electrostatic forces. The NRH and PRH adsorbents had a relatively large adsorption capacity (18.1 and 26.6 $\mathrm{mg} / \mathrm{g}$ ). The adsorbent PRH had a higher surface charge at alkaline $\mathrm{pH}$ and enhanced removal of MG was obtained under alkaline conditions. Typical adsorption kinetics indicated the pseudo second-order kinetics behaviour. The adsorption isotherms obeys Langmuir isotherm model.

${ }^{*}$ Corresponding author: Fatma M. El-Demerdash, University of Alexandria Institute of Graduate Studies and Research, Department of Environmental Studies, 163 Horreya Avenue, P.O. Box 832, Alexandria 21526, Egypt, Tel: 2034295007; Fax: 2034285792; E-mail: eldemerdashf@yahoo.com

Received January 09, 2015; Accepted February 16, 2015; Published February 19,2015

Citation: El-Demerdash FM, Abdullah AM, Ibrahim DA (2015) Removal of Trihalo Methanes Using Activated Carbon Prepared from Agricultural Solid Wastes. Hydrol Current Res 6: 193. doi:10.4172/2157-7587.1000193

Copyright: (c) 2015 El-Demerdash FM, et al. This is an open-access article distributed under the terms of the Creative Commons Attribution License, which permits unrestricted use, distribution, and reproduction in any medium, provided the original author and source are credited. 
It was observed that the rate of adsorption improves with increasing temperature and the process is endothermic nature. The negative value of the change in Gibbs free energy $\left(\Delta \mathrm{G}^{\circ}\right)$ indicates that the adsorption of MG on PRH and NRH is feasible and spontaneous [6].

Currently, problems in drinking water treatment extend beyond the scope of taste and odour control. Much attention is being paid to the regulation and control of numerous organic and inorganic compounds in water. Concerns about the presence of Synthetic Organic Compounds (SOC) arose in 1960s. Beginning in the 1970s it was recognized that disinfection of water with chlorine gas or chlorinecontaining compounds led to the generation of organic compounds, collectively termed Disinfection By-Products (DBPs), which were suspected of having adverse effects on health $[1,2]$. In this regard, Natural Organic Matter (NOM) constitutes the key group of organics acting as precursors for DBP formation. It was also shown that pretreatment of water with ozone led to inorganic hazardous by-products such as bromates. For many decades, adsorption onto activated carbon has appeared to be one of the most reliable methods of NOM and DBP control. This type of treatment is usually conducted in GAC filters. These are usually placed after sand filtration and before disinfection, but, depending on the characteristics of the water and the object of the treatment, GAC filters may also be positioned at other locations within the treatment train $[1,2]$.

Agricultural and food industries create various waste matters that need to be utilized and convert in value added product. Carbonaceous materials such as coconut shell, palm shell, saw dust and tropical wood are some of the most common agricultural wastes shells used to produce activated carbon. In the present study the activated carbon was prepared from two carbonaceous agriculture wastes by chemical activation using ortho-phosphoric acid $\left(\mathrm{H}_{3} \mathrm{PO}_{4}\right)$ at $800 \pm 5^{\circ} \mathrm{C}$. Agricultural solid waste is one of the rich sources for low cost adsorbents besides industrial byproduct or natural material. Due to abundant availability, agricultural waste such as orange peel poses little economic value and moreover, creates serious disposal problems. Many agricultural by-products that are available at little or no cost for example chicken feathers, cassava waste, rice husks have been reported to be capable of removing substantial amounts of metal ion and organic pollutants from aqueous solutions $[4,7]$. Therefore, the present study was designed to obtain activated carbon from rise husk and wood and to analyse their internal structure through Scanning Electronic Microscopy (SEM). Moreover, it was proposed to measure their DPBs adsorption capacity.

\section{Material and Methods}

The activated carbons (commercial and synthetic) used in this study for water purification were four types:

1- The Commercial Activated Carbon (CAC): Provided by AlGomhoria Chemical Company; (Alexandria, Egypt).

2- Woody Activated Carbon (WAC): Wood was used as precursor for the preparation of activated carbon. The wood was cut into pieces of 2 to $3 \mathrm{~cm}$ in size, dried in sunlight for 2 days. The dried material was then soaked in solution of $\mathrm{H}_{3} \mathrm{PO}_{4}$ for one hour and kept at room temperature for 24 hours. Thereafter, the wood material was separated, air dried at room temperature and carbonized in muffle furnace at $320^{\circ} \mathrm{C}$ for $90 \mathrm{~min}$. The carbon was ground to powder then the activated carbon was washed with plenty of distilled water to remove residual acid, dried, sieved into 300 to $850 \mu \mathrm{m}$ (20-50 ASTM mesh) sizes and stored in a tight lid container for further adsorption studies [8].

3- Rice Straw Activated Carbon (RAC): Rice Straw, after collection dried at $105 \pm 5^{\circ} \mathrm{C}$ for 6 hours and cooled to ambient temperature in desiccators and was cut into pieces of 2 to $3 \mathrm{~cm}$ in size, then soaked in solution of $\mathrm{H}_{3} \mathrm{PO}_{4}$ for one hour and kept at room temperature for 24 hour. The straw material was separated; air dried at room temperature and was carbonized in muffle furnace at $320^{\circ} \mathrm{C}$ for $90 \mathrm{~min}$. The carbon was ground to powder then the activated carbon. The prepared AC from rice husk was magnified using electron microscope as shown in Figure 1 [9].

4- Activated Carbon activated by $\mathrm{H}_{2} \mathrm{O}_{2}(\mathrm{CCH})$ : Rice Straw, after collection dried at $105 \pm 5^{\circ} \mathrm{C}$ for 6 hours and cooled to ambient temperature in desiccators and was cut into pieces of 2 to $3 \mathrm{~cm}$ in size, then soaked in solution of $\mathrm{H}_{2} \mathrm{O}_{2}$ for one hour and kept at room temperature for 24 hour. The straw material was separated; air dried at room temperature and was carbonized in muffle furnace at $320^{\circ} \mathrm{C}$ for $90 \mathrm{~min}$. The carbon was ground to powder then the activated carbon [8]. THM and TOC were determined according to APHA using GCECD, Agilent 5890 and TOC analyser, respectively (APHA, 2012) [8].

\section{Results and Discussion}

\section{Total Organic Carbon (TOC)}

Results presented in Tables 1-3 and Figures 2-6 showed that, as the AC dose in $\mathrm{mg}$ increased, the removal of TOC increased; at $10 \mathrm{mg}$ dose of $\mathrm{AC}$, the order of removal efficiency of TOC was

\begin{tabular}{|c|c|c|c|c|c|}
\hline \multirow{2}{*}{ Parameter } & \multirow{2}{*}{ AC Dose(mg/L) } & \multirow{2}{*}{$\begin{array}{c}\text { Commercial carbon } \\
\text { (CAC) }\end{array}$} & \multicolumn{3}{|c|}{ Synthesized AC } \\
\hline & & & $\mathrm{CCH}$ & RAC & WAC \\
\hline \multirow{11}{*}{ 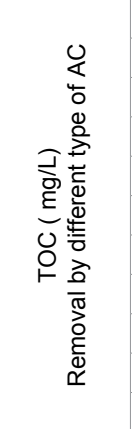 } & 0 & 5.7 & 5.9 & 5.8 & 5.2 \\
\hline & 2 & 4.3 & 4.3 & 5.1 & 4.9 \\
\hline & 6 & 4.0 & 4.2 & 4.8 & 4.7 \\
\hline & 10 & 3.6 & 4.1 & 4.6 & 4.3 \\
\hline & 14 & 3.2 & 3.9 & 4.2 & 4.0 \\
\hline & 16 & 2.9 & 3.7 & 3.6 & 3.9 \\
\hline & 18 & 2.4 & 3.3 & 2.8 & 3.7 \\
\hline & 20 & 1.9 & 3.1 & 2.6 & 3.1 \\
\hline & 22 & 1.6 & 2.9 & 2.0 & 2.9 \\
\hline & 24 & 1.4 & 2.5 & 1.7 & 2.7 \\
\hline & 26 & 1.2 & 2.2 & 1.4 & 2.4 \\
\hline Average & 15.80 & 2.93 & 3.65 & 3.51 & 3.80 \\
\hline Minimum & 2.00 & 1.20 & 2.20 & 1.40 & 2.40 \\
\hline Maximum & 26.00 & 5.70 & 5.90 & 5.80 & 5.20 \\
\hline
\end{tabular}

Table 1: Removal of TOC using different low cost adsorpant (AC).

\begin{tabular}{|c|c|c|c|c|c|}
\hline \multirow{2}{*}{ Parameter } & \multirow{2}{*}{ AC Dose(mg/L) } & \multirow{2}{*}{$\begin{array}{c}\text { Commercial Carbon } \\
\text { (CAC) }\end{array}$} & \multicolumn{3}{|c|}{ Synthesized AC } \\
\hline & & & $\mathrm{CCH}$ & RAC & WAC \\
\hline \multirow{10}{*}{ 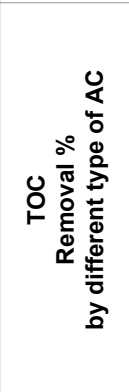 } & 2 & 24.3 & 24.3 & 9.7 & 14.4 \\
\hline & 6 & 29.6 & 25.7 & 15.3 & 17.4 \\
\hline & 10 & 37.3 & 27.8 & 18.3 & 23.8 \\
\hline & 14 & 43.7 & 32.0 & 26.1 & 29.9 \\
\hline & 16 & 49.6 & 34.2 & 35.7 & 31.9 \\
\hline & 18 & 58.1 & 41.9 & 50.0 & 35.6 \\
\hline & 20 & 66.7 & 45.4 & 53.5 & 44.9 \\
\hline & 22 & 71.8 & 49.3 & 65.1 & 49.6 \\
\hline & 24 & 76.1 & 56.9 & 71.0 & 52.8 \\
\hline & 26 & 78.3 & 60.9 & 76.1 & 58.8 \\
\hline Average & 15.8 & 53.55 & 39.84 & 42.08 & 35.91 \\
\hline Minimum & 6.00 & 24.30 & 24.30 & 9.70 & 14.40 \\
\hline Maximum & 26.00 & 78.30 & 60.90 & 76.10 & 58.80 \\
\hline
\end{tabular}

Table 2: Removal percentage of (TOC) using different low cost adsorpant(AC). 
Citation: El-Demerdash FM, Abdullah AM, Ibrahim DA (2015) Removal of Trihalo Methanes Using Activated Carbon Prepared from Agricultural Solid Wastes. Hydrol Current Res 6: 193. doi:10.4172/2157-7587.1000193

\begin{tabular}{|c|c|c|c|c|}
\hline $\begin{array}{c}\text { Max \% } \\
\text { (Removal) }\end{array}$ & $\begin{array}{c}\text { Min \% } \\
\text { (Removal) }\end{array}$ & $\mathbf{K}$ & $\mathbf{R}^{2}(\mathbf{1} / \mathbf{n})$ & AC \\
\hline 78.3 & 24.3 & 1.9914 & 0.955 & $\mathbf{C A C}$ \\
\hline 60.9 & 24.3 & 2.6075 & 0.9905 & $\mathbf{C C H}$ \\
\hline 76.1 & 9.7 & 1.347 & 0.9503 & RAC \\
\hline 58.8 & 14.4 & 2.314 & 0.9634 & WAC \\
\hline
\end{tabular}

Table 3: Freundlich coefficient for the TOC adsorption isotherms.

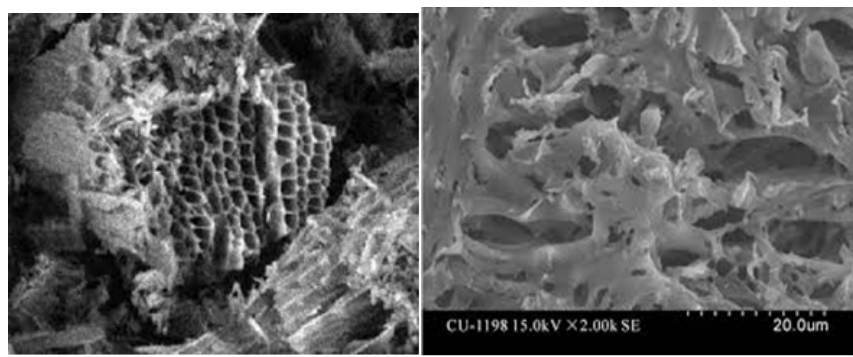

Figure 1: Scanning Electronic Microscopy of AC prepared from rice husk.

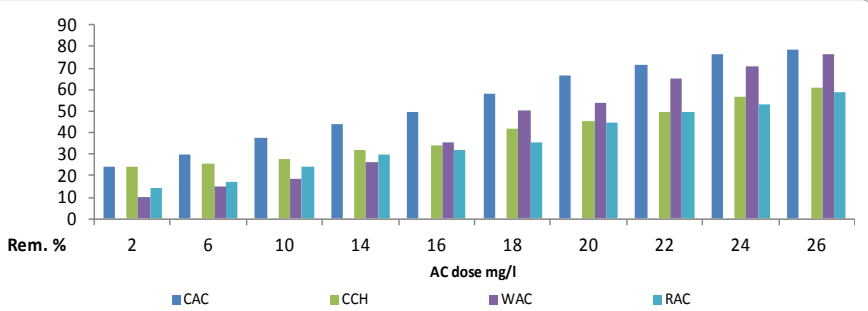

Figure 2: TOC removal \% using different low cost of AC.

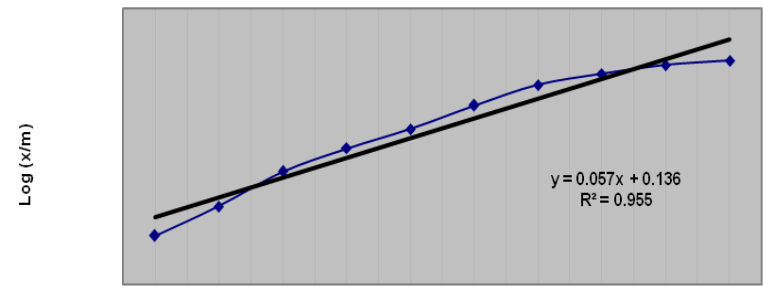

$\log (C)$

Figure 3: Frendlich isotherms for the TOC adsorption by CAC.

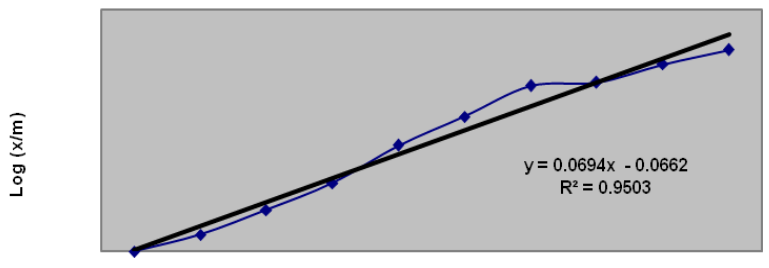

$\log (C)$

Figure 4: Frendlich isotherms for the TOC adsorption by RAC.

$\mathrm{CAC}>\mathrm{RAC}>\mathrm{CCH}>\mathrm{WAC}$, respectively. Among the four experimental carbons (CCH, CAC, RAC and WAC) The data from Table 3 indicates that in terms of adsorption of TOC organic compounds in the CAC tests, showed that, the highest performance (78.3\%) followed by
RAC (76.1\%), CCH (60.9\%), and WAC (58.8\%). Activated carbon activated with hydrogen peroxide $(\mathrm{CCH})$ had the highest $1 / \mathrm{n}$ value (0.9905) followed by WAC (0.9634), and commercial activated carbon without activation CAC (0.955) and RAC (0.9503). These values of $1 / \mathrm{n}$ corresponding to the respective carbons indicate that $\mathrm{CCH}$ has the highest rate of adsorption of the solute and RAC the least. These values of $1 / \mathrm{n}$ for $\mathrm{CCH}$ and RAC also suggest that within the chemical activation, carbon dioxide-activation improves $1 / \mathrm{n}$ compared to the other types of carbons. Furthermore, $\mathrm{CCH}$ with $1 / \mathrm{n} \approx 1.0(0.9905)$ indicates that the change observed in adsorbed solute (organic contaminants) concentration is greater than that occurred in the solute concentration. It is evident that, the commercial CAC were exceeded in removal of TOC composite organic compounds than that in case of prepared AC (CCH, RAC and WAC) (Figures 2 a-e) [10].

The removal of organic precursors of disinfection by-products (DBPs), i.e. natural organic matter (NOM), prior to disinfection is considered as the most effective approach to minimize the formation of DBPs. Trihalomethanes (THMs) as the main group of DBPs are categorized and considered to have the potentiality of increasing the rate of liver, kidney and central nervous system adverse effects [11]. NOM is primarily composed of humic substances, such as humic acids (HA) and fulvic acids (FA) that result from decomposition of terrestrial and aquatic biomass, but it can contain a range of organic species and microorganisms and their discharges [10]. The present results are in agreement with the finding of Carrière et al. [12]; who used powdered activated carbon in conjunction with polyaluminum chloride in TOC removal and proved that with adding only $11 \mathrm{mg} / \mathrm{l}$ of powdered activated carbon, TOC removal efficiency was improved and taste and odour agents were decreased (Figure 3).

Among the four experimental carbons, the commercial carbon CAC exceeded RAC and WAC in their adsorption performance. The physically activated carbon (steam and carbon dioxide) were superior in their adsorption to chemically activated, this could be due to the inhibition of small organics from penetrating into the micro-pores due to the presence of greater number of polar compounds on the mesopore and macropore surface of the acid activated carbons. These

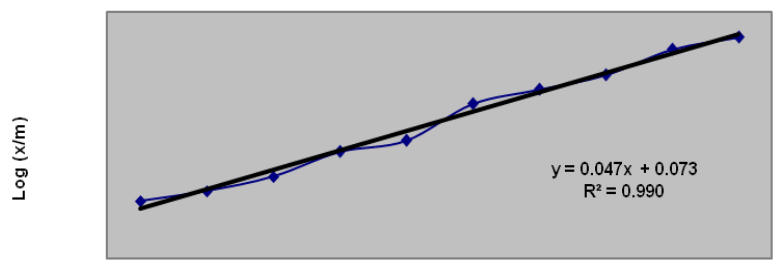

$\log (C)$

Figure 5: Freundlich isotherms for the TOC adsorption by $\mathrm{CCH}$.

WAC

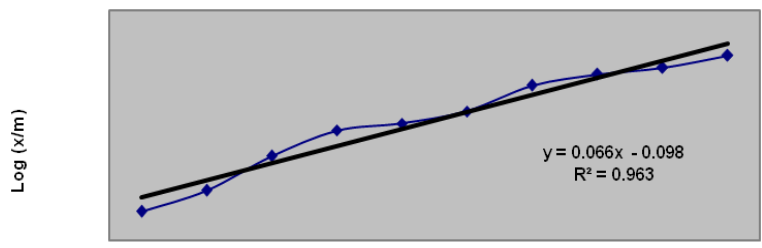

$\log (C)$

Figure 6: Frendlich isotherms for the TOC adsorption by WAC. 
Citation: El-Demerdash FM, Abdullah AM, Ibrahim DA (2015) Removal of Trihalo Methanes Using Activated Carbon Prepared from Agricultural Solid Wastes. Hydrol Current Res 6: 193. doi:10.4172/2157-7587.1000193

Page 4 of 6

data infer that the method of activation and precursors selected for the preparation of activated carbons do affect the adsorption of organic compounds and hence are factors to be considered in any adsorption process $[13,14]$. Also, in agreement with the present results, Abdulla [2] reported that AC removed TOC by $78 \%$.

Pre-chlorination has potential to increase DBP levels during water treatment process. Many treatments really on pre-chlorination to solve operational problems, including turbidity, algae growth control, inorganic oxidation and microbial inactivation as well as taste and odour $[1,2]$. So, in the present study, AC was used to show the effect of treatment on THM without the necessity to pre-chlorination. Five characteristics of carbon are important in the adsorption of organic molecules from solution. Yenisoy-Karakas et al. [14] reviewed several articles in the literature and suggested that these factors are (1) particle size, (2) surface area, (3) chemisorbed oxygen, (4) hardness and uniformity, and (5) pore structure. These adsorptive characteristics of carbon depend upon the sourcematerial of the carbon and the activation process [14].

Although adding powdered activated carbon enhanced organic matter removal, it caused decreasing coagulant consumption. For the application of poly aluminium chloride, by increasing the amount of powdered activated carbon, TOC was decreased and the least rate of TOC achieved at $100 \mathrm{mg} / \mathrm{l}$ powdered activated carbon [14]. Activated carbon adsorption has been widely applied in removing organic matters from wastewater as it has a strong affinity for attaching organic substances even at low concentration. Having large surface area for adsorption, granular activated carbon (GAC) is one of the best adsorbents for removing various organic contaminants $[2,14]$. The GAC adsorption systems are therefore considered to apply for producing the effluent of high quality from sewage treatment plant which can be reused for various purposes. However, even though it has high adsorption capacity, GAC can only maintain its adsorption for a short time after its available adsorption site becomes exhausted with adsorbed organic pollutants [15].

\section{THM}

Results presented in Tables 4-6 and Figures 7-11 showed that, as the $\mathrm{AC}$ dose in $\mathrm{mg}$ increases the THM removal increased; the order of removal of THM is $\mathrm{CAC}>\mathrm{RAC}>\mathrm{WAC}>\mathrm{CCH}$ respectively. The data presented in Table 6 the adsorption of THM organic compounds in the CAC tests, showed that the highest performance (45\%) followed

\begin{tabular}{|c|c|c|c|c|c|}
\hline \multirow{2}{*}{ Parameter } & \multirow{2}{*}{ AC Dose(mg/L) } & \multirow{2}{*}{$\begin{array}{c}\text { Commercial Carbon } \\
\text { (CAC) }\end{array}$} & \multicolumn{3}{|c|}{ Synthesized AC } \\
\hline & & & $\mathrm{CCH}$ & RAC & WAC \\
\hline \multirow{11}{*}{ 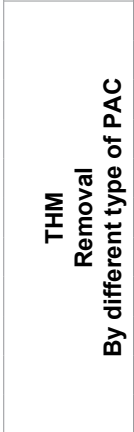 } & 0 & 69.0 & 54.9 & 65.7 & 64.2 \\
\hline & 2 & 57.8 & 50.8 & 57.8 & 59.7 \\
\hline & 6 & 51.0 & 50.0 & 51.1 & 57.5 \\
\hline & 10 & 44.3 & 48.6 & 44.3 & 54.8 \\
\hline & 14 & 38.6 & 45.5 & 38.6 & 53.0 \\
\hline & 16 & 35.1 & 42.8 & 35.1 & 51.7 \\
\hline & 18 & 31.5 & 38.3 & 31.5 & 47.6 \\
\hline & 20 & 31.51 & 37.6 & 31.5 & 45.2 \\
\hline & 22 & 31.4 & 37.3 & 31.4 & 41.9 \\
\hline & 24 & 31.2 & 37.0 & 31.2 & 42.1 \\
\hline & 26 & 27.1 & 37.1 & 27.1 & 39.6 \\
\hline Average & 14.36 & 40.8 & 43.6 & 40.48 & 50.66 \\
\hline Minimum & 2.00 & 27.10 & 37.00 & 27.10 & 39.60 \\
\hline Maximum & 26.00 & 57.80 & 50.80 & 57.80 & 59.70 \\
\hline
\end{tabular}

Table 4: Removal of THM using different low cost adsorpant (AC).

\begin{tabular}{|c|c|c|c|c|c|}
\hline \multirow{2}{*}{ Parameter } & \multirow{2}{*}{ AC Dose(mg/L) } & \multirow{2}{*}{$\begin{array}{c}\text { Commercial Carbon } \\
\text { (CAC) }\end{array}$} & \multicolumn{3}{|c|}{ Synthesized AC } \\
\hline & & & $\mathrm{CCH}$ & RAC & WAC \\
\hline \multirow{10}{*}{ 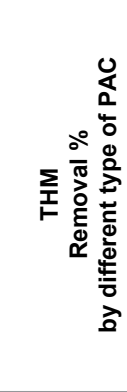 } & 2 & 16.2 & 7.5 & 12.0 & 7.0 \\
\hline & 6 & 26.1 & 8.9 & 22.2 & 10.4 \\
\hline & 10 & 35.8 & 11.5 & 32.6 & 14.6 \\
\hline & 14 & 44.1 & 17.1 & 41.2 & 17.4 \\
\hline & 16 & 49.1 & 22.0 & 46.6 & 19.5 \\
\hline & 18 & 54.3 & 30.2 & 52.1 & 25.9 \\
\hline & 20 & 54.3 & 31.5 & 52.1 & 29.6 \\
\hline & 22 & 54.5 & 32.1 & 52.2 & 34.7 \\
\hline & 24 & 54.8 & 32.6 & 52.5 & 34.4 \\
\hline & 26 & 60.7 & 32.4 & 58.8 & 38.3 \\
\hline Average & 15.80 & 42.37 & 21.21 & 39.48 & 21.71 \\
\hline Minimum & 2.00 & 16.20 & 7.50 & 12.00 & 7.00 \\
\hline Maximum & 26.00 & 60.70 & 32.60 & 58.80 & 38.30 \\
\hline
\end{tabular}

Table 5: Removal percentage of THM using different low cost adsorbent (AC).

\begin{tabular}{|c|c|c|c|c|}
\hline $\begin{array}{c}\text { Max \% } \\
\text { (Removal) }\end{array}$ & $\begin{array}{c}\text { Min \% } \\
\text { (Removal) }\end{array}$ & $\mathbf{K}$ & $\mathbf{R}^{\mathbf{2}(\mathbf{1} / \mathbf{n})}$ & $\mathbf{A C}$ \\
\hline 60.7 & 16.2 & 0.2268 & 0.7688 & $\mathbf{C A C}$ \\
\hline 22.6 & 7.5 & 0.2688 & 0.8968 & $\mathbf{C C H}$ \\
\hline 58.8 & 12 & 0.2265 & 0.7689 & $\mathbf{R A C}$ \\
\hline 23.6 & 7 & 0.0753 & 0.9703 & WAC \\
\hline
\end{tabular}

Table 6: Frendlich coefficient for the THM adsorption isotherms.

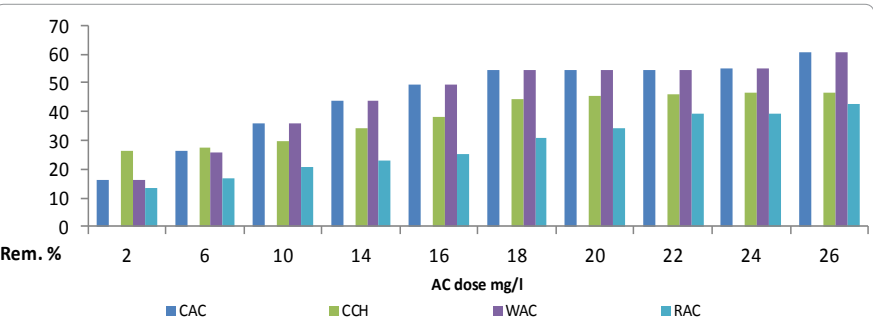

Figure 7: THM removal \% using different low cost of AC.

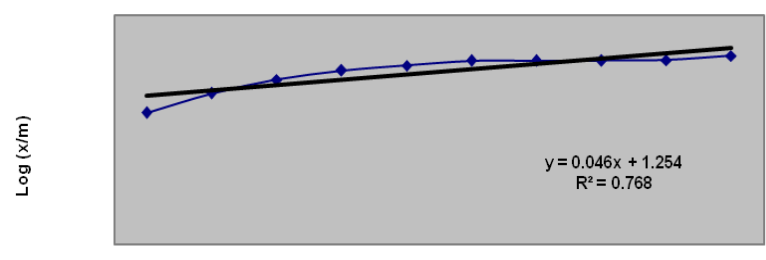

$\log (C)$

Figure 8: Frendlich isotherms for the THM adsorption by CAC.

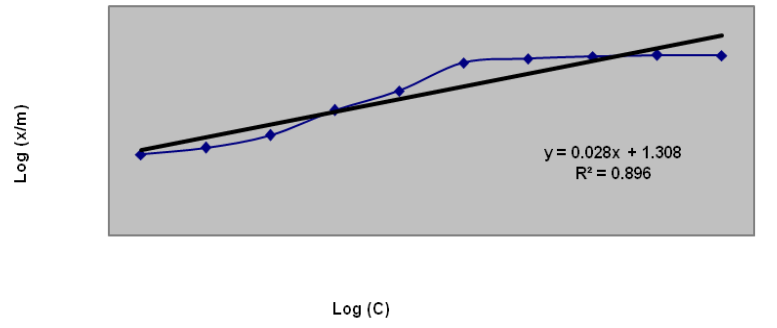

Figure 9: Frendlich isotherms for the THM adsorption by $\mathrm{CCH}$. 
Citation: El-Demerdash FM, Abdullah AM, Ibrahim DA (2015) Removal of Trihalo Methanes Using Activated Carbon Prepared from Agricultural Solid Wastes. Hydrol Current Res 6: 193. doi:10.4172/2157-7587.1000193

Page 5 of 6

by RAC (42.2\%), WAC (23.2\%) and CCH (22.6 \%). Woody activated carbon (WAC) had the highest $1 / \mathrm{n}$ value $(0.9703)$ followed by $\mathrm{CCH}$ (0.8968), RAC (0.7689) and CAC (0.7688). These values of $1 / \mathrm{n}$ corresponding to the respective carbons indicate that WAC has the highest rate of adsorption of the solute while RAC and CAC have the lowest rate. These values of $1 / \mathrm{n}$ for WAC and $\mathrm{CCH}$ also suggest that within the chemical activation carbon improves $1 / \mathrm{n}$ compared to the other types of carbons. Furthermore, WAC with $1 / \mathrm{n} \approx 1.0(0.0 .9703)$ indicated that the change in adsorbed solute (organic contaminants) concentration is greater than the change in the solute concentration [1]. Also, this is in agreement with Abdullah [2] who reported that AC removed $84 \%$ of THM. Moreover, Uyat et al. [16] studied the removing DBPs precursors by enhanced coagulation and powdered activated carbon (PAC) adsorption and proved that supplementing enhanced coagulation with PAC adsorption increased the removal of TOC to $76 \%$ and PAC adsorption removed mostly low molecular weight and uncharged natural organic matter (NOM) substances as indicated in Figures 7-11 [12,16].

\section{Factors affecting AC adsorption capacity}

Effect of solution $\mathbf{p H}$ : The $\mathrm{pH}$ of the solution is one of the major factors influencing the adsorption capacity of the compounds that can be ionized. In order to study the effect of the $\mathrm{pH}$, several experiments were carried out with carbon $\mathrm{CCH}$ at a temperature of $25^{\circ} \mathrm{C}$ using different initial solution $\mathrm{pH}$ of values $(2.0,7$ and 9). The $\mathrm{pH}$ of the solutions are maintained by means of ionic buffer solutions composed with $\mathrm{NH}_{4} \mathrm{OH}, \mathrm{HCl}, \mathrm{KH}_{2} \mathrm{PO}_{4}, \mathrm{Na}_{2} \mathrm{HPO}_{4}, \mathrm{NaH}_{2} \mathrm{PO}_{4}$ and Citric acid. The effect of $\mathrm{pH}$ on the isotherms CCH for TOC is presented in Figure 12. It indicated that at very low $\mathrm{pH}(\mathrm{pH}=2)$, the amount of TOC adsorbed is lower than those obtained with other $\mathrm{pH}$ due to the competition with $\mathrm{H}^{+}$on carbonyl sites [4,7]. The effects of $\mathrm{pH}$ on the elimination efficiency of TOC using powdered activated carbon showed that the optimum $\mathrm{pH}$ range between 5.5 and 6 [2,17].

As a result, at $\mathrm{pH} 7$, the rate of TOC reduction was $76 \%$. Taking into consideration the closeness to the natural $\mathrm{pH}$ of water, this showed the high efficiency of powdered activated carbon in the natural $\mathrm{pH}$ of water. It has also shown that a considerable reduction in total organic carbon concentration is obtained in $\mathrm{pH}$ ranges of 5.5 to 7 . This is due to the fact that TOC solubility decreased and organic matter adsorption increased in this ambient $\mathrm{pH}$. The increase of $\mathrm{pH}$ favoured the ionization of organic matter and decreasing the $\mathrm{pH}$ could redound to neutralize the negative charge on the surface of powdered activated carbon using hydrogen ions as indicated in Figure $4[2,17]$.

Effect of solution temperature: It is clear from the present results that the TOC adsorption decreases with increasing temperature as shown in Figure 13. This well-known effect of temperature is expected for physical adsorption that is exothermic in nature in most cases (USEPA and Hoang $[11,15]$. Due to this temperature dependence of adsorption capacity, the adsorption isotherms have been determined in a thermostatic bath at $25^{\circ} \mathrm{C}$. Ramaraju et al. showed that, the rate of adsorption improves with increasing temperature and the process is endothermic nature [6].

\section{Conclusion}

Drinking water treatment using activated carbon (AC) is one option for treatment of drinking water problems. AC is an effective method for treating certain organic compounds, unpleasant tastes and odours, and chlorine, as well as its effective for metals, microbial contaminants, algae and other inorganic contaminants. Adsorption capacity of activated carbon had been found to be dependent on the adsorbent dosage but other variables such as adsorbate concentration, $\mathrm{pH}$ variation, activating reagents, temperature have their own effect on adsorption capacity. Hence this prompts the use of different model to carry out analysis of the adsorption capacity (Fruendlich isotherm). Adsorption process can be well understood through isotherms resulting between adsorbate concentration in liquid and amount of adsorbate adsorbed by unit mass of adsorbent at a constant temperature. The present results obtained by the adsorption experiment were analysed by Freundlich, isotherms. TOC and THM could be effectively removed by $\mathrm{AC}$ adsorption from drinking water. The fitting result indicated that the adsorption of THM on RAC represents the linear consistency. External mass from TOC from tap water, contact time and mixing

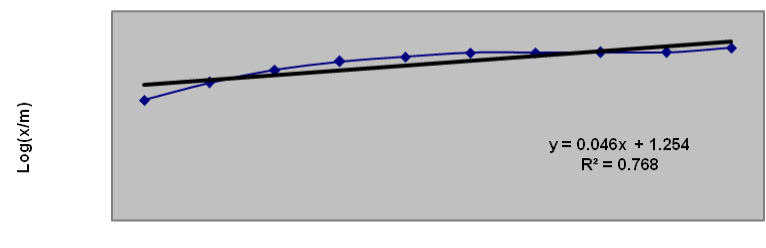

$\log (\mathrm{C})$

Figure 10: Frendlich isotherms for the THM adsorption by RAC.

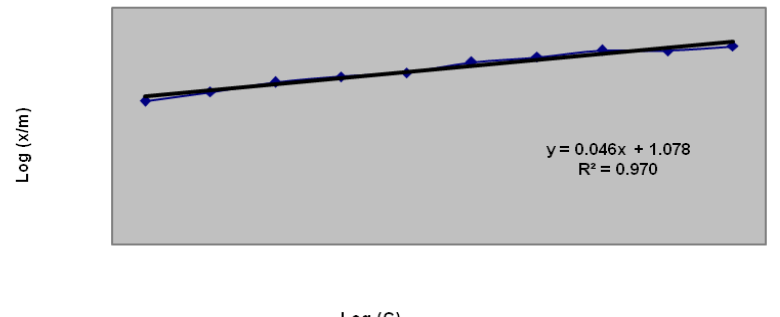

Figure 11: Frendlich isotherms for the THM adsorption by WAC.

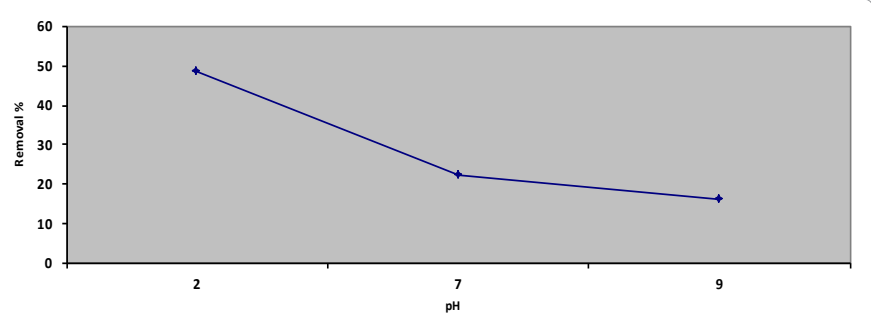

Figure 12: Effect of solution $\mathrm{pH}$.

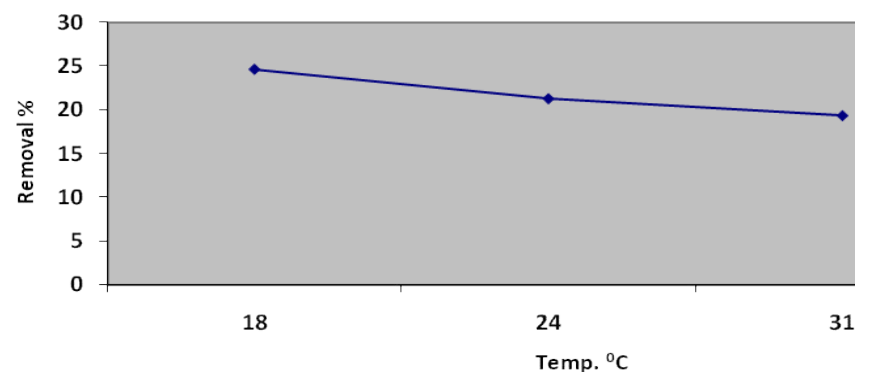

Figure 13: Effect of solution temperature. 
Citation: El-Demerdash FM, Abdullah AM, Ibrahim DA (2015) Removal of Trihalo Methanes Using Activated Carbon Prepared from Agricultural Solid Wastes. Hydrol Current Res 6: 193. doi:10.4172/2157-7587.1000193

were confirmed as controlling step in the sorption process. Under the prevailing conditions, the maximum RAC removal efficiency was found to be $58.8 \%$ for $65.7 \mu \mathrm{g} / \mathrm{l} \mathrm{THM}$ with contact of $0.026 \mathrm{~g}$ of RAC.

\section{References}

1. Slavinskaya GV (1991) Chlorination effect on quality of drinking water. Khimiya I Tekhnol. Vody 13: 1013-1022.

2. Abdullah AM (2012) Alexandria University, Alexandria, Egypt.

3. Dibinin MM, Plavnik GM, Zevarina EF (1964) Integrated Study of the Porous Structure of Activated Carbon from Carbonized Sucrose. Carbon 2, 261.

4. Yang T, Lua AC (2003) Characteristics of activated carbons prepared from pistachio-nut shells by physical activation. J Colloid Interface Sci 267: 408-417.

5. Amaral CS, Míriam C, Lange C, Liséte Borges, Cristiano P, et al. (2014) Evaluation of the use of powdered activated carbon in membrane bioreactor for the treatment of bleach pulp mill effluent. Water Environ. Res 86: 788-799.

6. Ramaraju B, Manoj Kumar Reddy P, Subrahmanyam C (2014) Low cos adsorbents from agricultural waste for removal of dyes. Environ Prog Sust Energy 33: 38-46.

7. Bansal RC, Goyal M (2005) Middle East Technical University, Ankara, Turkey.

8. Daud WM, Ali WS (2004) Comparison on pore development of activated carbon produced from palm shell and coconut shell. Bioresour Technol 93: 63-69.
9. Daud WMAW, Houshamnd AH (2010) Textural characteristics, surface chemistry and oxidation of activated carbon. Journal of Natural Gas Chemistry 19: $267-279$

10. Alvarez-Uriarte JI, Iriarte-Velasco U, Chimeno-Alanis N,Gonzales-Velasco JR (2010) The effect of mixed oxidants and powdered activated carbon on the removal of natural organic matter. J Hazard Mater 181: 426-431.

11. USEPA, United States Environmental Protection Agency (2001) Controlling disinfection by-products and microbial contaminants in drinking water. Washington: USEPA, Office of research and development.

12. Carrière A, Vachon M, Bélisle JL, Barbeau B (2009) Supplementing coagulation with powdered activated carbon as a control strategy for trihalomethanes: application to an existing utility. J. Water Supply Res 58: 363-371.

13. Kurosaki F, Ishimaru K, Hata T, Bronsveld P, Kobayashi E, et al. (2003) Microstructure of wood charcoal prepared by flash heating. Carbon 41: 3057-3062.

14. Yenisoy-Karakas v, Aygün A, Günes M, Tahtasakal E (2004) Physical and chemical characteristics of polymer-based spherical activated carbon and its ability to adsorb organics. Carbon 42: 477-484.

15. Hoang TTL (2005) University of Technology, Sydney.

16. Uyat V, Yavuz S, Toroaz I, Ozaydin S, Genceli EA, et al. (2001) Disinfection by-products precusors removal by enhanced coagulation and PAC adsorption. Desalination 216: 334-344.

17. Reed BE, Jensen JN, Matsumoto MR (1993) Acid-base characteristics of powdered-activated-carbon surface. J. Environ Eng ASCE 119: 585-590. 